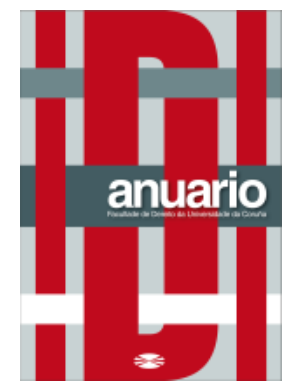

Anuario da Facultade de Dereito da Universidade da Coruña

Vol. 22 (2018), pp. 214-232

ISSNe: 2530-6324 || ISSN: 1138-039X

DOI: https://doi.org/10.17979/afdudc.2018.22.0.5184

\title{
EL COMERCIO ELECTRÓNICO DE OBRAS PLÁSTICAS: APROXIMACIÓN A UNA REALIDAD EN CUBA
}

\author{
LUIS PÉREZ OROZCO \\ Asesor Jurídico de la Universidad de Matanzas (Cuba)
}

Resumen: El comercio electrónico consiste en la compra y venta de productos o de servicios a través de medios electrónicos, como Internet y otras redes informáticas. Constituye uno de los ámbitos de mayor investigación científica y más actividad en la creación de marcos normativo-legales. Concede en el domicilio de una persona una gran oferta de bienes y servicios de forma sencilla y rápida. Entre esos bienes que se pueden adquirir están las obras de arte. Hoy día, marchantes y galerías de arte cuentan con un sitio en Internet que les permite enlazar con mercados virtuales. El comprador y el vendedor puedan encontrarse rápidamente desde dos ubicaciones geográficas distantes. Cuba es un país que no queda ajeno a esta dinámica, pues los autores de obras plásticas viabilizan la comercialización de sus creaciones utilizando el Internet. Pero, si bien el comercio electrónico representa muchísimas facilidades para el binomio artista-cliente, su uso trae aparejado inconvenientes legales e inseguridad jurídica. Por tanto, la presente investigación se circunscribe a la descripción de la situación de iure y de facto sobre el comercio electrónico de obras plásticas cubanas. Todo ello motivado por una cuestión que cada vez más cobra auge en la práctica: el aumento del interés en el arte cubano, ya sea por inversión o goce estético.

Palabras clave: Obra plástica, comercio electrónico, Ley de Derecho de Autor, Cuba.

Abstract: The e-commerce it's the purchase and sale of products or services through electronic medias, such as the Internet and other computer networks. It's one of the 
areas of greater scientific research and more activity in the creation within the framework of the law. Grants a great offer of goods and services in a person's home easily and quickly. Among those personal properties that can be acquired are plastic arts. Today, dealers and art galleries have a website that allows them to link with virtual markets. The buyer and seller can be quickly found from two distant geographical locations. Cuba it's a country that isn't quite oblivious of this dynamic, because the authors of plastic arts make viable the commercialization of their creations using the Internet. But, while e-commerce represents many facilities for binomial artist-client, it's use brings with legal problems and insecurity. Therefore, this investigation is limited to the description of the de jure and de facto situation regarding the electronic trade of Cuban plastic arts. All of this motivated by an issue that's trending upward: the increase of interest in Cuban art, whether by investment or aesthetic enjoyment.

Key words: Plastic art, e-commerce, Copyright Law, Cuba.

SUMARIO: 1. INTRODUCCIÓN.- 2. LAS OBRAS PLÁSTICAS COMO OBJETO DEL DERECHO DE AUTOR.- 3. LA COMPRAVENTA DE OBRAS PLÁSTICAS CUBANAS.- 4. EL ARTE CUBANO A UN CLIC DE DISTANCIA: PAUTAS PARA ENTENDER EL COMERCIO ELECTRÓNICO COMO FENÓMENO CONTEMPORÁNEO.- 5. A MODO DE CONCLUSIONES.

\section{INTRODUCCIÓN}

La adquisición de obras plásticas constituye un fenómeno social, cultural y jurídico, donde confluyen intereses como el goce estético o la realización de un negocio. Históricamente, esa relación entre artistas y clientes (compradores) ha sido entendida desde la concurrencia física entre ambos sujetos. Sin embargo, el pujante desarrollo de las tecnologías de la información y las comunicaciones (TICs) han transformado esa dinámica, en la que ahora también intervienen otros agentes que hacen atractivo un producto y saben comercializarlo mediante la red de redes. Se trata de nuevas facilidades y oportunidades para los involucrados en la compraventa de obras plásticas, pero que también implica transitar hacia un contexto en el que puede vulnerarse la seguridad jurídica del tráfico negocial per saltum si el ordenamiento legal no ampara esa particular transacción.

En este fenómeno de compraventa de obras plásticas mediante el comercio electrónico, interactúan el Derecho Civil, Administrativo, Informático y el de Autor, siendo este último al que se le prestará más énfasis. Acerca del Derecho de Autor, en Cuba contribuyen a la conformación de una doctrina nacional destacadas juristas como Caridad del Carmen VALDÉS DÍAZ, Lilian ÁLVAREZ NAVARRETE y Beatriz LÓPEZ TRIANA por solo citar algunos. Sin embargo, esas investigaciones no analizan la situación del comercio electrónico que tiene como objeto a las obras plásticas. Tanto dentro como fuera del país, existen sitios web especializados en la venta de esos bienes, un fenómeno al que el ordenamiento jurídico interno todavía no le ha dado respuesta. 
No existe en Cuba una legislación para la regulación del comercio electrónico en general y de las obras plásticas en particular; pues las normativas vigentes datan de la década de los años 70 y hasta los primeros años de este siglo, cuando la informatización no se había expandido de una manera tan vertiginosa.

Por tanto, se definió como Objetivo General de esta investigación describir la actividad comercial electrónica con obras de la plástica cubana y la postura que asume el ordenamiento jurídico nacional al respecto. Se prefirió solo realizar un análisis expositivo, pues se persigue visibilizar una realidad que no es debidamente atendida por el Estado. Abundar sobre posibles soluciones desborda los marcos de esta ponencia y la extensión requerida para su publicación. En aras de alcanzar el fin investigativo propuesto se utilizaron como métodos el deductivo-inductivo, análisis-síntesis y sociológico.

\section{LAS OBRAS PLÁSTICAS COMO OBJETO DEL DERECHO DE AUTOR}

El Derecho de Autor es la rama de las Ciencias Jurídicas que regula los derechos subjetivos del autor (persona física que crea la obra) sobre las creaciones que presentan individualidad resultante de su actividad intelectual, que habitualmente son enunciadas como obras. Pero, ¿qué criterios deben seguirse para que esas creaciones sean protegibles? Deben ser creaciones formales y no ideas, originales, no dependen de su valor, mérito, destino o forma de expresión y además no están sujetas a formalidades.

En este contexto al autor le son reconocidos diversidad de derechos, los que se pueden clasificar en morales y patrimoniales. Los primeros integran el derecho a la divulgación, reconocimiento de la paternidad, respeto a la integridad y el retracto o arrepentimiento. Se caracterizan por ser extrapatrimoniales y en principio tienen duración ilimitada. Los segundos conforman la reproducción, comunicación pública y transformación por citar los más conocidos. Pueden ser objeto de distintas limitaciones a su ejercicio y su duración, a diferencia de los anteriores, es limitada.

En Cuba, la Disposición Final Primera del Código Civil ordena que las relaciones jurídicas relativas a la creación de obras científicas, educacionales, literarias y artísticas se rigen por la legislación especial. Es entonces la Ley No. 14 de 28 de diciembre de 1977 la normativa encargada de regular todo lo relacionado con el Derecho de Autor, además, de resultar aplicables los diferentes Convenios internacionales sobre la materia que el país ha firmado y ratificado.

Según la Ley de Derecho de Autor en Cuba existen diferentes tipos de obras originales, y de ellas resultan de particular interés para esta investigación las obras plásticas, las que aparecen reconocidas en el artículo 7 inciso h. Previamente, es imprescindible realizar precisiones en torno a los diferentes términos utilizados por la doctrina para referirse a este tipo de obras. Se recurre frecuentemente a la expresión "creaciones visuales" para identificar en una figura amplia una lista de creaciones imposibles de describir de forma exhaustiva y sobre la cual no existe un total consenso aún. Para la mayoría de los autores el término comprende las creaciones que tradicionalmente se han ubicado dentro del campo de las obras plásticas, a saber: la pintura, dibujo, escultura, grabado, litografía, arquitectura, fotografía, entre otras. Algunos consideran que abarca también las obras audio visuales e incluso las llamadas creaciones visuales 
contemporáneas como el performance, las instalaciones y el video arte. ${ }^{1}$ Otro vocablo de uso común en esta esfera del derecho autoral sobre las obras objeto de este estudio es "arte", de ahí que algunos autores utilicen expresiones como "obras de artes plásticas" y "obras de artes visuales".

Deberá entenderse, cualquiera que sea el término utilizado, que el autor de esta investigación se refiere a las obras plásticas tradicionalmente consideradas como tal. Con razón ESPÍN CÁNOVAS ha señalado la dificultad de conceptualizar la obra plástica como grupo concreto, excepto en el caso de los géneros tradicionales como la pintura, la escultura y el grabado. ${ }^{3}$ Según BERCOVITZ las obras de artes plásticas "son aquellas que se manifiestan por medio de la forma y el color, se da forma o color a la materia preexistente. De ahí la importancia de las líneas, los planos, las dimensiones, los volúmenes, la intensidad y la variedad de los colores y de sus tonalidades". ${ }^{4}$

Indudablemente, la obra plástica como creación humana refleja un ámbito determinado de la realidad y produce una reacción individual en el espectador que la observa, o sea, una sensación diferente en cada persona al contemplar la obra, de acuerdo con sus ideales y sentido estético, conformándose distintas opiniones relativas a ella. El Convenio de Berna no fija un concepto, sino que en su artículo 2, al referirse a las obras protegidas incluye, dentro de las obras artísticas, las de dibujo, pintura, arquitectura, escultura, grabado, litografía, las obras de arte aplicado, las obras fotográficas, además de las expresadas por procedimientos análogos a la fotografía; las ilustraciones, mapas, planos, croquis y obras plásticas relativas a la geografía, a la topografía, a la arquitectura o a las ciencias.

La Ley de Derecho de Autor, hace una enumeración de la mayoría de las creaciones que integran las obras plásticas en el ya mencionado artículo 7 inciso h) cuando establece: "(...) las obras de dibujo, pintura, arquitectura, escultura, grabado, litografía, escenografía, diseño y otras similares" y en el inciso i) de ese propio precepto al regular "(...) las obras fotográficas y otras de carácter similar". Se trata de menciones ejemplificativas, lo que se acentúa, no sólo por la utilización de la frase "fundamentalmente" en el enunciado del referido precepto 7, sino también, cuando se hace uso de los términos "otras similares" y "otras de carácter similar" respectivamente. De esta manera queda abierta la posibilidad de brindar protección a nuevos tipos de creaciones que se originen como resultado de los avances y del desarrollo en el campo tecnológico. La Resolución No. 5 del 2002 del Ministerio de Cultura establece una definición de obras de artes visuales en el artículo 1 al señalar "las obras de artes visuales a las que se hace referencia en este Reglamento son aquellas que tienen como característica común utilizar una imagen fija como imagen de exposición". Sin

\footnotetext{
${ }^{1}$ TRIANA LÓPEZ, B., "Reflejo de las especiales características de la obra plástica en la sucesión mortis causa del Derecho de Autor", Anuario de la Facultad de Derecho, Vol. XXVII, 2009, p. 375.

${ }_{2}^{2}$ ANTEQUERA PARILLI, R., Estudios de derecho de autor y derechos afines, Editorial Reus S.A., Madrid, 2007, p. 70.

${ }^{3}$ ESPÍN CÁNOVAS, D., "Las obras de las artes plásticas en la Ley de Propiedad Intelectual de 11 de noviembre de 1987", en DELGADO PORRAS, A., Estudio sobre Derecho Industrial. Homenaje a Hermenegildo Baylos, Barcelona, Grupo Español de A.I.P.P.I., 1992, p. 327.

${ }^{4}$ BERCOVITZ RODRÍGUEZ-CANO, R., "Comentarios al artículo 10 de la Ley de Propiedad Intelectual", en BONDÍA ROMÁN, F. y RODRÍGUEZ TAPIA, J. M., Comentarios a la Ley de Propiedad Intelectual, Editorial Civitas, Madrid, 1997, p. 179.
} 
embargo, TRIANA LÓPEZ considera que ya no resulta adecuado hablar únicamente de imagen fija como imagen de exposición, pues existen en la actualidad numerosos artistas plásticos cuyas obras no tienen esta característica, como es el caso de las llamadas obras cinéticas (que incluyen movimiento). Es de señalar que al igual que la Ley de Derecho de Autor, utiliza en su artículo 2.1 un enunciado ejemplificativo de las obras de artes visuales que regula la norma y hace uso de esta expresión, que como ya se vio es más abarcadora que "obras plásticas" y ello permite la incorporación de nuevos tipos de obras a la protección que ofrece.

Como todo tipo de obra, la obra plástica debe ser resultado del intelecto humano para ser considerada como tal y consecuentemente, merecedora de la tutela jurídica que brinda el Derecho de Autor. Ello implica el ejercicio de una actividad creativa personal, una actividad intelectual que implica creación en tanto aporte individual del que resulta una forma de expresión original.

Una de las principales características es la originalidad de la obra plástica, que en este caso puede encontrarse en su concepción plástica, en su ejecución, o en ambas fases de su realización. En las obras plásticas, frecuentemente viene dada mucho más por su ejecución que por su concepción que puede carecer de originalidad. Concretamente, tanto en la pintura como en la escultura, la técnica y sensibilidad del artista en la ejecución de la obra son decisivas para su originalidad y para su valoración en general. En las creaciones plásticas, el original de este tipo de obras tiene una vital importancia toda vez que cualquier imitación, aun cuando logre un alto grado de perfección, tiene un valor insignificante con respecto al original y cualquier ejemplar posterior tiene un valor distinto dada la imposibilidad de transmitir los mismos valores estéticos y plásticos que contiene la ejecución original, de ahí la importancia que esta reviste en este tipo de obra. No obstante, en el campo de las artes plásticas no debe asumirse que la originalidad radica sólo en la concepción plástica de la obra o en su ejecución. ${ }^{5}$ En algunos casos se protege la concepción plástica específica y no un tema genérico y lo que se busca a través de la ejecución es fijar dicha concepción. En otros supuestos la originalidad esencial está en la impronta personal que implica la ejecución plástica de la obra por el autor. ${ }^{6}$ Estima TRIANA LÓPEZ que sea en una u otra o en ambas -concepción plástica o ejecución de la creación- siempre que se aprecie una forma de expresión original persona y creativa con características originales, estaremos ante una obra protegida por el Derecho de Autor.

La originalidad de la obra plástica tiene influencia, incluso determinante, en otras características de este tipo de creación. Así el droit de suite o derecho de seguimiento se refiere sólo a la reventa de obras que son originales. Otra característica es que en ella, dan lugar a la obra final una conjunción de varios elementos, a saber, el color, la materia y la forma. El color, según plantea Hans Hofman es "en sentido científico un estado

\footnotetext{
5 “(...) Resulta evidente la necesidad de que la obra tenga un "mínimo de originalidad”, es decir, que demuestre una variación importante con respecto a otras obras acerca del tema que representan o a la manera en que son realizadas, hablando siempre de temas ya existentes en el momento de realización de la obra plástica concreta. También aparecerá dicha originalidad cuando la obra recoja un tema o una manera de elaboración no conocida hasta el momento". Vid. ORTEGA DOMÉNECH, J., Obra plástica y derechos de autor, Editorial Reus, S.A., Madrid, 2000, p. 92.

${ }^{6}$ BERCOVITZ RODRÍGUEZ-CANO, R., op. cit., p. 179.
} 
específico de la luz, en el sentido artístico la percepción de las diferencias plásticas y psicológicas de la cualidad de la luz". Esas diferencias se conciben como intervalos de color, similares a las tensiones, la expresión de fuerzas relacionadas entre dos o más formas sólidas. En la naturaleza la luz crea la sensación de color; en un cuadro el color crea la luz. ${ }^{7}$ Con respecto a la materia Hofman señala que los medios de expresión de una obra son "los medios materiales gracias a los cuales se da forma a ideas y emociones". ${ }^{8}$ Dada la peculiaridad que tiene la obra plástica de necesitar la fijación material para obtener la protección del Derecho de Autor, esta puede ser papel, tela, piedra, etc. La utilización de uno u otro tipo de materia le brinda un sello personal a la obra. La forma es necesaria para elaborar la obra. Al decir de HOFMAN "va mucho más allá de una simple constatación física". Se trata de interrelacionar diversas formas en una obra plástica para darle el sentido buscado con su creación". ${ }^{9}$

Una vez acabada la obra, su significado va más allá de dicha forma, puesto que se trata de un instrumento para establecer una relación de lo creado con una cierta realidad evocada materialmente. ${ }^{10}$ Como ya se ha apuntado, la obra plástica necesita fijación material para obtener su protección y justamente esto es así porque para ser considerada obra no basta con la existencia de la idea en la mente del autor, puesto que esta no es objeto de protección, se necesita que la creación se exteriorice de alguna manera recognoscible, ${ }^{11}$ cualquiera que esta sea. ${ }^{12}$ De ahí, una de las características más relevantes de la obra plástica: la unicidad, que significa la existencia de una íntima relación entre la creación como obra del intelecto humano y el soporte material en que esta se exterioriza.

Las obras de arte también forman parte de lo que se viene conociendo como bienes tangibles de colección, es decir, aquellos objetos que por su peculiar singularidad van, paulatinamente, aumentando su valor a través del tiempo. Son bienes que tienen un valor a través del tiempo y que tienen un valor intrínseco, a la vez que su posesión puede aportar un goce estético.

\section{LA COMPRAVENTA DE OBRAS PLÁSTICAS CUBANAS}

Las facultades resultantes del Derecho de Autor pueden ser transmitidas por actos inter vivos y mortis causa, pero no todas están sometidas a la misma posibilidad ni al mismo régimen. Es objeto de esta ponencia la transmisión por actos inter vivos y mediante

\footnotetext{
${ }^{7}$ HOFMAN, H., cit. pos. ORTEGA DOMÉNECH, J., op. cit., p. 47.

${ }^{8}$ Ididem., p. 45

${ }^{9}$ Ibidem., p. 48.

${ }^{10}$ ORTEGA DOMÉNECH, J., op. cit., pág. 48

${ }^{11}$ Debe tenerse en cuenta que, aunque en los géneros tradicionales como la pintura, la escultura, el dibujo, entre otros, la creación se exterioriza mediante soportes físicos, no ocurre lo mismo en el caso de algunas creaciones visuales contemporáneas en las que se utilizan como medio de expresión recursos que pueden ser tangibles (papel, lienzo, madera), intangibles (las ondas acústicas, por ejemplo) o el performance, cuyo medio de expresión suele ser el cuerpo humano. Para un estudio más detallado de estos tipos de obras. Vid. ORTEGA DOMÉNECH, J., op. cit., págs. 93-94.

${ }^{12}$ El Convenio de Berna en su artículo 2.2 establece que se reserva a las legislaciones de los países de la Unión la facultad de establecer que "las obras literarias y artísticas o algunos de sus géneros no estarán protegidos mientras no hayan sido fijados en un soporte material”. La ley autoral cubana señala en su artículo 2 las obras a las que se refiere el derecho de autor que regulan sus preceptos "(...) cualquiera que sean sus formas de expresión".
} 
contratos las facultades patrimoniales, dirigiendo la atención únicamente a la compraventa como negocio jurídico.

El artículo 28 de la Ley de Derecho de Autor expone que, mediante el contrato, el autor o sus derechohabientes pueden ceder el derecho a utilizar una obra a una entidad autorizada a estos fines, en la forma y bajo las condiciones que en dicho contrato se estipulen, de acuerdo con lo dispuesto en la legislación vigente sobre esta materia. El precepto continúa reconociendo la posibilidad de la existencia de varios tipos de contratos en materia autoral, tales como el de edición, el de representación o ejecución pública, el relativo a la obra cinematográfica, y el de creación de una obra por encargo. La redacción de este artículo le otorga al régimen contractual el carácter de numerus apertus, por lo que también se pueden reconocer otros negocios jurídicos como los Derecho Civil, por ejemplo, el de compraventa de obra.

Según el artículo. 29 todo contrato para la utilización de una obra debe reunir los siguientes requisitos, fundamentalmente: los nombres de las partes contratantes, el título de la obra, el derecho cedido, el término de la cesión, la forma y el grado de utilización de la obra y la cuantía y los plazos para hacer efectiva la remuneración correspondiente, así como la determinación de las condiciones y los casos en los que el autor puede o no ceder su obra a terceras personas, para su utilización total o parcial, durante la vigencia del contrato. Seguidamente el artículo 30 exige que todo contrato para la utilización de una obra debe ser concertado por escrito; y establece excepciones a este requerimiento. Respecto al negocio jurídico que es objeto de estudio en esta investigación, resulta muy importante lo regulado en el precepto 21 de la Ley de Derecho de Autor al establecer que la venta de una obra de artes plásticas o de cualquier otra clase de manuscrito, confiere al adquirente solo la propiedad del objeto material. El autor conservará el derecho de autor sobre su obra.

Se debe dejar por sentado que la compraventa es un contrato cuyo efecto principal es la transmisión de la propiedad al producirse la entrega de los objetos sobre los cuales recaen. El que dispone de un bien mediante este contrato debe ser su propietario, aunque la compraventa de bienes ajenos también puede surtir efectos jurídicos. ${ }^{13}$

¿Cuáles pueden ser las motivaciones para que un usuario decida comprar una obra? Satisfacer deseos personales, incorporación en una colección, construir un complemento a la inversión en activos financieros (más característico de países capitalistas) o simplemente goce estético. Resulta que en la actualidad el arte se ha convertido en un objeto con valor que cumple la ley de la oferta y la demanda. A este mecanismo se le denomina mercado del arte y es el ámbito virtual donde interactúan la oferta y la demanda de un producto único e irrepetible, por su creación. El mercado del arte tiene características propias que radican en la dedicación a la transacción de objetos únicos por lo que requiere que los agentes tengan un alto nivel de información. Resulta entonces este tipo de negocio muy peculiar: por su objeto, los sujetos que intervienen y el mercado.

\footnotetext{
${ }^{13}$ Apud. VALDÉS DÍAZ, C. del C., Estudios cubanos sobre Derecho de Autor y derechos conexos, La Habana, Ediciones ONBC, 2014, pp. 258-260.
} 
Esos sujetos (comúnmente conocidos como agentes del mercado del arte) que generalmente intervienen en este tipo de negocio son: artistas, marchantes (comerciantes que compran y venden las obras, por lo que obtienen una comisión), galeristas (actúan como gestores o representantes artísticos y marchantes), coleccionistas, museos, consultor de arte, el Estado (posibilidad de ejercer derecho de tanteo y de retracto) mediante ferias de arte, casas de subastas e Internet.

En Cuba el Decreto-Ley No. 106 de 5 de agosto de 1988 dispuso que las obras de artes plásticas y aplicadas se comercializan por las entidades que designe el Ministerio de Cultura, a las que corresponde con exclusividad, la compra de los objetos producidos por los creadores artísticos independientes. La Resolución No. 48 de 1989 de ese Ministerio designó al Fondo de Bienes Culturales de ese organismo para ejecutar, con exclusividad, las referidas operaciones de compra a los fines de la ulterior comercialización de las creaciones artísticas.

En su doble misión económica y cultural, en la última década asume nuevos roles en su empeño de representar, promover y comercializar, nacional e internacionalmente, las obras de los creadores de las artes plásticas y las artes aplicadas —y los servicios asociados de diseño e interiorismo - con un reconocido sello de calidad que jerarquiza el valor estético y preserva los valores patrimoniales. En la actualidad la empresa comercializa con más de 8000 creadores a través de su amplia red de tiendas y galerías ubicadas en todas las provincias del país y el municipio especial Isla de la Juventud. Mediante esta red comercial se ofertan productos que se distinguen por su calidad, autenticidad y variedad, capaz de satisfacer los más exigentes gustos. Sus servicios de restauración, ambientación y diseño, que oferta a entidades y a personas naturales, se basan en el trabajo de grupos creativos multidisciplinarios, en los que artesanos y artistas de diversas ramas complementan sus habilidades para crear proyectos con verdadera maestría.

Una importante parte de sus ingresos son destinados a la adquisición de materias primas, materiales, equipos, herramientas, accesorios, insumos y bienes para el trabajo de los artistas y artesanos cubanos, con el fin de impulsar el potencial creativo y salvaguardar las conquistas culturales de la sociedad cubana.

En este contexto también juega un importante rol la Agencia de Autores Visuales $(\text { ADAVIS })^{14}$ creada mediante la Resolución No. 119 de 2001 del Ministerio de Cultura.

\footnotetext{
${ }^{14}$ La Resolución No. 119 de 2001 del Ministerio de Cultura autoriza para el desarrollo de las atribuciones conferidas a ADAVIS en Cuba, y en el extranjero a través de las organizaciones homólogas a ella en el mundo, el ejercicio de las funciones siguientes: la gestión, bajo la modalidad de mandato representativo, establecido en acta, a favor de los autores y titulares; la concesión de las autorizaciones individuales a los utilizadores para las explotaciones de tales derechos sobre las obras de las artes visuales; la recaudación de las remuneraciones producto de la concertación de voluntades o a partir de las cuotas tarifarias establecidas a este efecto, generadas de las utilizaciones de las obras dentro del marco de la cesión de derechos autorizada; la recaudación de las cantidades percibidas en concepto de las indemnizaciones generadas como producto de las sanciones por explotaciones no autorizadas, dictadas contra utilizadores, conforme a la ley; el reparto, conforme a la legislación bancaria vigente, de la expresión económica de los derechos recaudados y de las indemnizaciones que se establezcan; la concertación, en armonía con sus funciones, de contratos de representación, unilaterales y recíprocos, con sus homólogas en todo el mundo, y la transferencia mutua de sus correspondientes repertorios de autores de obras presente y posteriormente confiadas para su gestión; la instauración de tarifas base correspondientes al pago por las utilizaciones lucrativas o no
} 
En uno de sus Por Cuanto reconoce que resulta cada vez mayor el auge internacional alcanzado por los autores de las artes plásticas del país, lo que fundamenta la necesidad de la creación de una entidad de gestión de derechos de autor de las artes visuales que vincule al creador a la suerte económica que las utilizaciones independientes a la venta en el territorio nacional, en ambas monedas, reportan a favor de sus explotadores; así como que represente y gestione la cesión y recaudación internacional de los montos como producto de la utilización de las obras de los autores en todo el mundo.

En el Resuelvo Segundo se establece que la misión de la ADAVIS será la gestión a nombre del autor y los demás titulares de los derechos exclusivos de reproducción, distribución, transformación y comunicación pública sobre las obras de las artes visuales, con las atribuciones de representación, cesión, recaudación, reparto y distribución de las remuneraciones, provenientes de las utilizaciones de las obras de los autores componentes de su repertorio.

Es oportuno aclarar que, con la apertura del trabajo por cuenta propia, surgieron nuevas modalidades laborales; sin embargo, no se incluyó la compraventa de obras de arte. Para conocer cuáles actividades al sector cuentapropista le están permitidas es fundamental remitirse a la Resolución No. 12 de 2018 del Ministerio de Trabajo y Seguridad Social.

La actividad autorizada número 82 consiste en la restauración de obras de arte, si son obras del patrimonio cultural requiere la aprobación del Consejo Nacional de Patrimonio Cultural, no puede comercializar estas obras; y la número 120, Pintor callejero, solo puede reflejar a través de su arte la arquitectura colonial del Centro Histórico de La Habana Vieja y realizar caricaturas. Ergo cualquier persona natural que se dedique a esta función está actuando al margen de lo establecido legalmente y puede ser sujeto de una multa administrativa o de acusación penal por el delito de Actividad Económica Ilícita. ${ }^{15}$ Además, pueden resultar de aplicación las contravenciones de las

de los derechos reconocidos a los titulares sobre las obras en explotación; la concertación de acuerdos generales con los utilizadores, organizaciones de utilizadores, autores, titulares, organizaciones de autores u otras personas naturales y jurídicas para la gestión de los derechos sobre las obras de su repertorio, presentes y futuras.

${ }^{15}$ Ley No. 62 de 29 de diciembre de 1987 Código Penal de la República de Cuba, artículo 228: "1. El que, con ánimo de lucro, realice cualquiera de las actividades de producción, transformación o venta de mercancías o prestación de servicios de las autorizadas legal o reglamentariamente sin poseer la licencia correspondiente; o realice alguna actividad de esa naturaleza no autorizada en forma expresa por disposición legal o reglamentaria, incurre en sanción de privación de libertad de tres meses a un año o multa de cien a trescientas cuotas o ambas. 2. Si para la realización de los hechos a que se refiere el apartado anterior, se contratara mano de obra o se utilizaran medios o materiales de procedencia ilícita, la sanción es de privación de libertad de uno a tres años o multa de trescientas a mil cuotas o ambas. 3. El que no obstante poseer la licencia correspondiente, contrate mano de obra o utilice medios o materiales de procedencia ilícita, o incumpliera lo establecido en los reglamentos a fin de obtener mayores ganancias, incurre en sanción de privación de libertad de seis meses a dos años o multa de doscientas a quinientas cuotas o ambas. 4. No se considerarán delitos los hechos previstos en los apartados anteriores cuando se trate de actividad de reducida significación económica, excepto los casos señalados en los apartados 1 y 2 , cuando en su realización se utilicen medios o materiales de procedencia ilícita. apartados anteriores puede imponérseles, además, la sanción accesoria de confiscación de bienes”. 
regulaciones en materia de política cultural y sobre la prestación de servicios artísticos. $^{16}$

No obstante, el arte cubano no se mantiene solamente en ese marco; pues hoy día las TICs han permitido que los bienes de cualquier naturaleza puedan venderse mediante el Internet. Es una situación harto conocida que la penetración de la red de redes en Cuba es un asunto prioritario para el Gobierno, pero aún está en desarrollo, y para ello se ha establecido una política de informatización de la sociedad. En julio del 2016, en el país se desarrolló una prueba piloto para implementar la pasarela de pago que facilite el despliegue de plataformas web para el comercio electrónico. ${ }^{17}$ Sin embargo, tanto desde el territorio nacional como extra fines determinadas personas se dedican a la venta de arte cubano, y lo hacen utilizando plataformas informáticas interconectadas.

\section{EL ARTE CUBANo A UN CLIC DE Distancia: PAUTAS PARA ENTENDER EL COMERCIO ELECTRÓNICO COMO FENÓMENO CONTEMPORÁNEO}

El comercio electrónico constituye uno de los ámbitos de mayor investigación científica y más intentos en la creación de marcos normativo-legales. "Sin embargo, hoy en día, los esfuerzos legales puramente digitales escasean y el corpus principal de leyes sobre derecho de autor antecede a las últimas revoluciones tecnológicas; al mismo tiempo, es importante notar que una de las fuerzas más importante de cambio puede ser el uso y la costumbre. En otras palabras, gran parte de lo que ofrece internet aún no ha sido explorado, y mientras continúe el desarrollo de la interconectividad mundial, con seguridad conoceremos nuevas posibilidades que hoy resultan imposibles de considerar". ${ }^{18}$

Se trata de un servicio que apoyado fundamentalmente en la tecnología permite la realización de operaciones de negocios y la compraventa de bienes y servicios mediante la utilización de sistemas electrónicos. Concede en el domicilio de una persona una gran oferta de bienes y servicios de forma sencilla y rápida. Se diferencia del net art, en que este consiste en la creación de obras digitales y para su comercialización en la red de redes.

\footnotetext{
${ }^{16}$ Decreto No. 349 de 20 de abril de 2018 sobre las contravenciones de las regulaciones en materia de política cultural y sobre la prestación de servicios artísticos.

${ }^{17}$ Según datos aportados en el evento científico internacional Informática 2018 por Alberto Quiñones, Director General de Servicios Informáticos del Banco Central de Cuba (BCC), funcionan 936 cajeros en la Isla; de ellos, 4 permiten el cambio de monedas y 7 tienen la capacidad de reciclar. En cuanto a las tarjetas magnéticas se creció en más de un $17 \%$ al plan previsto en 2017 , contando hoy con más de 4 millones de tarjetas activas. Para el 2018 se estima un aumento similar. Es importante señalar que el $90 \%$ de las operaciones que se realizan es para extraer dinero por lo que se pretende que la tarjeta magnética sea un medio de pago con una aceptación más eficiente. El desarrollo del comercio y el gobierno electrónico en el país son puntos cardinales en la estrategia de informatización de la nación, la cual no solo aspira a tener una sociedad más interconectada, sino facilitar la interacción de las entidades productivas, de servicio y de gobierno con la ciudadanía.

18 WUHL, F., “¿Derecho de autor o propiedad intelectual? Nuevas posibilidades en internet”, en CASANOVAS, I.; GÓMEZ, M. G. y RICO, E. J. (editores), Actas de las III Jornadas de Investigación en Edición, Cultura y Comunicación, Buenos Aires, 2015, p.161.
} 
Hoy día, marchantes y galerías de arte cuentan con sitios en Internet que permiten enlazar a mercados virtuales. La compra en línea se ha rápidamente democratizado para las obras del mercado secundario ${ }^{19}$ (artistas ya conocidos) y funciona cada vez mejor para algunas obras del mercado primario ${ }^{20}$, como fotografías o grabados. Los compradores y vendedores en Internet dan prioridad al circuito más rápido, menos costoso en términos de gastos y más líquido, al que permite encontrar un precio de mercado en tiempo real con una masa crítica de participantes. Las traducciones en varios idiomas y los servicios de alerta de correo electrónico son algunas de las soluciones estudiadas para que el comprador y el vendedor puedan encontrarse rápidamente desde dos ubicaciones geográficas distantes. De forma que, Internet ha pasado de ser un instrumento de promoción a convertirse en una herramienta esencial de compra y venta.

Al plantearse la puesta en marcha de una galería de arte en Internet se tienen en cuenta las principales razones para que un usuario se inicie en la compra de productos a través de la red: la comodidad para realizar la compra, el precio o las promociones que pueden conseguirse, la exclusividad del medio, las facilidades para comparar ofertas y obtener información sobre productos o servicios, la mayor y más diversa oferta de productos o servicios, la rapidez del suministro, el hecho de que tenga curiosidad por el medio y por ello le impulse a probar la compra por Internet por vez primera ¿Qué caracteriza a los sitios web dedicados a la venta de obras de arte? Están bien enfocados en cuanto a los contenidos y oferta de servicios, alta capacidad para ofrecer obra de artistas de renombre, trato directo del comprador con el marchante, conocimiento por parte del comprador de la obra y el artista, acceso del comprador a herramientas que le permiten ubicar la obra en el entorno del local, color de pintura o tamaño de la pared, obras certificadas, no se comprometen con ninguna línea artística concreta, transmite calidad y cuentan con información sobre cómo realizar la venta y ofrece información económica.

Son variadas las tecnologías utilizadas por el comercio electrónico de obras de arte. Una de ellas es la multimedia, que consiste en cualquier objeto que usa simultáneamente diferentes formas de contenido informativo como texto, sonido, imágenes, animación y video para informar o entretener al usuario.

También es muy empleado el correo electrónico que permite a los usuarios enviar y recibir mensajes rápidamente mediante sistemas de comunicación electrónicos. Su eficiencia, conveniencia y bajo coste están logrando que el correo electrónico desplace al correo ordinario para muchos usos habituales.

Por su parte, los tableros electrónicos de publicidad son equipos modulares y flexibles, que permiten gran diversidad de tamaños, colores y configuraciones. Permiten variados

\footnotetext{
${ }^{19}$ El mercado secundario está compuesto por obras que han sido vendidas como mínimo en una ocasión. Si un coleccionista, un marchante o una galería revenden una obra que ya ha sido objeto de transacción, la obra pasa al mercado secundario. La mayoría de las reventas se produce en salas de subastas, aunque no únicamente allí. No son pocos los profesionales especializados en la recompra y la reventa de común acuerdo.

${ }^{20}$ Con la expresión mercado primario se designa a las obras que son puestas a la venta por primera vez. Se trata de obras frescas, salidas directamente del taller del artista. Esta producción inédita resulta particularmente estimulante.
} 
efectos de aparición de textos o gráficos para crear mensajes dinámicos e impactantes; conectar múltiples unidades en redes vía Protocolo de Control de Transmisión y Protocolo de Internet (Transmission Control Protocol/Internet Protocol o TCP/IP) o mediante modem por acceso telefónico. Son sistemas de fácil manejo y programación.

El CAD, acrónimo de Computer Aided Design, puede utilizarse para generar modelos con muchas, si no todas, de las características de un determinado producto. Además, pueden compartirse e integrarse las ideas combinadas de varios diseñadores, ya que es posible mover los datos dentro de redes informáticas, con lo que los diseñadores e ingenieros situados en lugares distantes entre sí pueden trabajar como un equipo.

El intercambio electrónico de datos (EDI, por sus siglas en inglés), es un conjunto de procedimientos y normas que permiten la comercialización, control y registro de las actividades (transacciones) electrónicas. Es el intercambio electrónico de datos y documentos de computador a computador, en un formato estándar universalmente aceptado, que se realiza entre una empresa y sus asociados comerciales. Para quien haya implementado el comercio electrónico en su empresa, el EDI, es un componente vital y estratégico para el intercambio seguro y a tiempo de la información de negocios.

La transferencia electrónica de fondos engloba a cualquier sistema que permite transferir dinero desde una cuenta bancaria a otra cuenta directamente sin ningún intercambio de dinero en metálico; por ejemplo, el pago con tarjeta, el pago a través de teléfono móvil o la banca electrónica a través de Internet.

El crecimiento global del comercio electrónico ${ }^{21}$ ha afectado a numerosos aspectos legales que incluyen: seguridad en la red y las transacciones, protección de los derechos de propiedad intelectual en el entorno digital; la gestión de los sistemas de pago; la legalidad de los contratos electrónicos; los aspectos de la jurisdicción ${ }^{22}$ en el

\footnotetext{
${ }^{21}$ Según datos de la empresa líder en información de mercado Nielsen, en una encuesta en la que participaron más de 27.000 usuarios de América, Asia-Pacífico, Europa y Oriente Medio, los continentes en que más usuarios han realizado compras online son Asia-Pacífico y Europa, ambos continentes con un $85 \%$ y seguidos de Norteamérica con un $83 \%$. Para los consumidores online de todo el mundo, siguiendo los datos de esa encuesta de Nielsen, los libros (44\%) y la ropa (36\%) son los artículos que planearon comprar a través de Internet en los seis meses siguientes, seguidos de billetes de avión (32\%), equipamiento electrónico (27 \%) y reservas de hotel (26 \%). En el año 2012, el número de usuarios de Internet se acercaba a 2.500 millones de personas. Los protagonistas del mundo del arte utilizan esta herramienta global en diversos ámbitos (sitios oficiales, redes sociales) para comunicar, promocionar, informarse, comprar y vender.

${ }^{22}$ El Código Civil Cubano en su artículo 13.1 estipula que "La forma de los actos jurídicos civiles se rige por la legislación del país en que se realizan". Lo que no ha tenido en consideración el legislador son aquellas situaciones especiales en que estando presente el elemento extranjero resulta difícil determinar cuál es lugar de celebración: la utilización de medios electrónicos. La red define, por sí misma, un nuevo espacio, sin ninguna conexión territorial precisa y en el que la información, al igual que la oferta y aceptación contractual, la prestación de ciertos servicios e incluso la entrega de ciertos productos, circulan de forma inmediata y automática. Un espacio donde además confluyen múltiples operadores con localizaciones territoriales diversas (consumidores, proveedores de servicios, o de redes). Los contratos electrónicos experimentan un crecimiento exponencial gracias a Internet y se derivan, en la mayoría de los casos, relaciones transfronterizas. En el Derecho Internacional Privado, un principio general es la autonomía de la voluntad de las partes, pero en este tipo de contratación muchas veces no se da la oportunidad de que las partes puedan fijar de acuerdo a su voluntad los aspectos fundamentales para realizar un contrato. Por ejemplo, al realizar una compra dese una página web, en esta ya se encuentran fijadas todas las condiciones impidiéndole intervenir en las cláusulas de contratación, por lo que el
} 
ciberespacio sobre ley aplicable y resolución de conflictos, pues poder ofrecer productos en Internet a todo el mundo a través de medios relativamente limitados ofrece grandes oportunidades, pero también es imprescindible saber dónde se resolverá un conflicto comercial; así como la ley de protección de datos que afectan en general a las personas, no sólo en los aspectos de relaciones comerciales.

De acuerdo con un estudio llevado a cabo por la Comisión Europea, las principales barreras que se encuentra el comercio electrónico para su expansión son: la falta de información y la desconfianza que suscita, en especial para las pequeñas y medianas empresas. Otros problemas básicos que implica el comercio electrónico de arte están el encubrimiento de acciones delictivas, ${ }^{23}$ las repercusiones legales en las compraventas privadas y la falta de autenticidad. ${ }^{24}$ La falsificación y la piratería han venido exigiendo la búsqueda de mecanismos o dispositivos de seguridad que alerten al público sobre la autenticidad o no de los productos puestos en el mercado. Más allá del tradicional precinto de seguridad, se han llegado a utilizar hologramas, tintas fotocromáticas, dispositivos electrónicos y otros. No obstante, como bien señala RODRÍGUEZ GÓMEZ, estos dispositivos presentan algunos problemas: no todos los tipos de obras pueden ser protegidos e identificados por estos métodos; los costes añadidos de tales medidas de seguridad no se justificarían para obras múltiples; y, por último, se trataría de precauciones a corto plazo, pues los falsificadores rápidamente tendrían a su disposición medios más sofisticados y rápidos para vulnerar dichas medidas. Por lo

comprador acepta o rechaza de manera general el contrato. Puesto que la autonomía se ve tan mermada, resulta de gran importancia determinar cuál será el lugar de celebración del contrato concertado por medios electrónicos, y a qué reglas ha de atenerse. HERNÁNDEZ FERNÁNDEZ aboga que cuando el oferente es una persona natural debe prevalecer el domicilio legal, y en ausencia de este su lugar de residencia o estancia. Cuando se trate de personas jurídicas el domicilio debe quedar recogido en sus estatutos o donde radique su órgano de dirección. Este asunto de la ley aplicable es aún más escabroso y así lo reconoce DÁVALOS FERNÁNDEZ: "la ley para calificar el acto jurídico es la ley cubana, y sin embargo, la que regula su forma es la del lugar donde se realiza (artículo 17), y la que rige su contenido, habrá de variar según se trate de relaciones sobre bienes, de obligaciones o de sucesiones (artículo 14.1)". Para ampliar sobre el comercio electrónico Vid. HERNÁNDEZ FERNÁNDEZ, L., "Artículo 13", en PÉREZ GALLARDO, L. B. (director). Comentarios al Código Civil Cubano, Tomo I, Vol. I, La Habana, Editorial Universitaria Félix Varela, 2013, pp. 217-223.

${ }^{23} \mathrm{Al}$ respecto el Grupo de Acción Financiera Internacional (GAFI) creado para prevenir el lavado de activos, estableció a través de sus tipologías regionales especialmente en Sudamérica, el lavado de activos mediante compraventa de obras de arte. Consiste en que el delincuente compra una obra de arte a un valor inferior a su precio de la reventa. Después se simula una venta de la obra de arte a un comprador ficticio en el exterior. El delincuente transfiere fondos propios de origen ilícito, depositados en una cuenta colocada en el exterior empleando un testaferro a su cuenta nacional. A continuación, aquella transferencia se justifica como ingreso por la venta de obra de arte.

${ }^{24}$ Según Walter BENJAMIN, "el aquí y ahora del original (refiriéndose a la obra) constituye el concepto de su autenticidad. La autenticidad de una cosa es la cifra de todo lo que desde el origen puede transmitirse en ella desde su duración material hasta su testificación histórica". Para el filósofo del arte Denis DUTTON, "una obra de arte auténtica es aquella cuyo origen, autoría y procedencia están correctamente identificados". Partiendo de este concepto se definirá "autentificación de una obra de arte" strictu sensu como "el proceso que establece si es correcta o verdadera la atribución de la autoría de una obra de arte a un determinado artista". La autentificación es un proceso en la medida en que para establecer si un artista es el autor de una obra de arte es necesario antes efectuar varios actos ordenados y encaminados a dicho fin. Es un proceso que exige ineludiblemente la creación o identificación de pruebas que verifiquen la relación de la obra de arte con el artista al que se atribuye su autoría. A veces se realizará sólo una, otras veces, muchas. La autoridad de la conclusión del proceso dependerá, entre otros factores, del número y valor probatorio de las pruebas aportadas. 
demás, debe tenerse en cuenta que muchos de estos dispositivos sirven para facilitar la diferenciación de un producto auténtico de uno falso, con lo cual, poco se puede hacer en aquellos casos en el que el propio cliente está dispuesto a comprar un producto con pleno conocimiento de que se trata de un producto falsificado o tiene dudas al respecto. $^{25}$

Además, cuando se realiza un negocio de este tipo son varios los datos que debe tener en cuenta el cliente: el precio (determinar el precio de una obra de arte exige una pericia notable ${ }^{26}$ ), la presentación de la obra, el lugar, la documentación, aptitud y condición profesional de las partes, examen de la obra, tiempo de posesión de la misma y la época. ¿Cómo entender la biografía del artista? ¿Cuál es la información clave y por qué? La edad de un artista es la primera información que se facilita en su biografía. Centrarse en esta cuestión permite conocer las repercusiones en el potencial de carrera. Posteriormente, atender su formación. Determinadas escuelas de prestigio son auténticas plataformas para los jóvenes titulados, que en ocasiones son llamados por las galerías apenas finalizan sus estudios. El artista laureado puede obtener más notoriedad, una publicación o una exposición. En Cuba la prensa especializada en arte no registra crónicas sensacionalistas, pero resulta esencial la notoriedad de sus críticos de arte y la categoría de sus lectores. En el caso de los artistas antiguos y modernos, la notoriedad depende de la impronta que hayan dejado en el mundo del arte plástico.

Para lograr esta caracterización fueron consultados los sitios web:

- www.subastahabana.com/index.php/es/como-comprar,

- www.amdyart.com/,

- www.cubautor.com/pinturascubanas/comprar.html,

- www.cubapinta.com,

- www.pintorescubanos.org/, www.cubaluxuryhotels.com/front/tourist_packages/view/comprando-arte...cuba/6/es

- www.revolico.com/compra-venta/arte/

De todos ellos, el que más información ofrece a sus potenciales clientes es Subasta Habana. Se trata de la casa subastadora de las artes plásticas cubanas. El Consejo Nacional de las Artes Plásticas constituye su Comisión Organizadora, y en uso de sus facultades, designó a la Galería Habana, para que actúe como mediadora entre el depositante-vendedor de cada bien y los posibles compradores en la subasta A Viva Voz y la Galería Virtual, respectivamente. Desde el año 2002 presenta obras de los más

\footnotetext{
${ }^{25}$ ORÉ SOSA, E., "Delitos contra el Derecho de Autor”, REDUR Revista Electrónica de la Universidad de La Rioja, No. 9, diciembre 2011, p. 346.

${ }^{26}$ La obra original y única resulta más costosa que una obra múltiple, ya que ofrece a los coleccionistas el atributo de rareza que buscan. Sin embargo, determinadas obras "originales" y "únicas" no son realizadas íntegramente por el artista, ya que muchos artistas trabajan con ayudantes o con proveedores externos. Generalmente, las obras múltiples son menos caras que los dibujos o las pinturas. Las obras múltiples deben ser puestas en circulación en una cantidad limitada. Cuanto más bajo es el número de ejemplares, más influye el criterio de rareza en el valor. Para estar seguro sobre la edición, se recomienda verificar el marcado de la obra (su número de ejemplares) y la presencia de la firma del artista. La notoriedad artística, mediática, las técnicas empleadas, los materiales, fecha de realización (determinados períodos están más cotizados que otros) y las dimensiones influyen también.
} 
prestigiosos artistas nacionales de todos los tiempos legitimados en el circuito internacional del arte.

Subasta Habana, a través de su sitio web, ofrece la posibilidad de acceder a los usuarios durante todo el año a su Galería Virtual y adquirir las obras de su selección; asimismo, estarán disponibles todas las obras que serán rematadas en la subasta A Viva Voz en la capital del país. La subasta A Viva Voz respetará como precio de partida la puja más alta por lote obtenida en el sitio mencionado. El adjudicatario del lote es responsable del pago de cualquier tasa e impuesto que exija la legislación vigente en Cuba o las leyes pertenecientes a los países por donde deba transitar y en el que vaya a permanecer definitivamente el lote adjudicado. En consecuencia, es responsabilidad del cliente revisar las tasas e impuestos aplicables que pueden ser añadidos a la pieza antes de pujar por ella.

Las condiciones de contratación de La Galería son las que se especifican a continuación, sin perjuicio de las que se puedan introducir en el futuro y que serán debidamente publicadas a través de los catálogos: el depositante-vendedor garantiza a La Galería y esta ha verificado que es el propietario de los bienes depositados o que depositará y que tiene el pleno dominio sobre los mismos, o que está válidamente autorizado por su propietario para disponer de estos, y que, por tanto, puede transferir su título, estando, además, libres de cargas o gravámenes; garantiza igualmente que ha facilitado toda la información que posee relativa a su procedencia y que no están sujetos a restricciones de propiedad intelectual, excepto cuando haya informado a La Galería lo contrario. En el caso excepcional de que los bienes u objetos no se depositen en La Galería o no se coloquen bajo control de esta, el vendedor garantiza que los mismos serán mantenidos en similar estado en el que se encontraban cuando fueron presentados, y que serán entregados cuando esta los solicite. El vendedor indemnizará a La Galería por cualquier daño o perjuicio sufrido a consecuencia de incumplir lo anteriormente establecido; y con carácter general, por cualesquiera de las obligaciones que asume, recogidas en estas Condiciones Generales.

Según el sitio web una vez recibida la confirmación del importe de pago por el cliente, será organizado el envío de la obra con su factura correspondiente y certificado de autenticidad, si se posee. A partir de ese momento se adquiere la propiedad de la obra. Todas las obras en Subasta Habana están avaladas por un Certificado de Autenticidad $^{27}$

\footnotetext{
${ }^{27}$ En el ámbito privado, suele ser muy frecuente que el juicio de autoría se plasme en un documento escrito, que adopta la denominación de Certificado de Autenticidad. Se suele exigir para aceptar la compra de una obra de arte de cierta importancia económica. Un certificado de autenticidad es una manifestación escrita de un experto o de un comité de expertos, pero también puede ser del artista, de un familiar, de un amigo, de un colaborador, que afirma la autenticidad o no de la obra. Es un documento que plasma el resultado de un proceso de autentificación realizado con anterioridad. Como cualquier otro documento escrito, puede ser objeto de falsificación. También puede ocurrir que un certificado auténtico se utilice para acreditar una obra que no es la auténtica que se presentó a certificar. El factor riesgo es mínimo para los artistas vivos, ya que los certificados de autenticidad son relativamente fáciles de obtener. Por el contrario, con las obras de artistas fallecidos, como se deduce, es preciso actuar con cautela. Para evitar inconvenientes, es imprescindible solicitar antes de la compra los documentos que acompañan a la obra. El Certificado de Autenticidad debe haber sido emitido por una persona autorizada por el artista o él mismo. Sobre su garantía pueden variar los criterios en dependencia de cada legislación nacional.
} 
emitido por un comité de expertos cubanos que garantiza la legitimidad de las mismas, excepto aquellas que fueron realizadas en el exterior. En el caso de los artistas vivos la certifica el propio autor. La compraventa no se considerará formalizada y la entrega no se efectuará hasta que la persona a la que se adjudique el lote no pague el importe total que facture la obra de arte y las demás cantidades debidas.

El resto de los sitios web visitados por el autor de esta investigación ofrecen muy poca información sobre las obras plásticas en venta y cómo se procede para adquirirlas. Algunos como Cuba Pinta está restringido su acceso, lo que implica inseguridad para realizar negocios con sus promotores y por tanto no es recomendable su uso.

\section{A MODO DE CONCLUSIONES}

La obra plástica se caracteriza por la originalidad, a la que tributa decisivamente la técnica y sensibilidad del artista en la ejecución de la obra. Es el resultado de una conjunción de varios elementos, a saber, el color, la materia y la forma. La utilización de uno u otro tipo de materia le brinda un sello personal a la obra. Además, tiene la peculiaridad de necesitar la fijación material para obtener la protección del Derecho de Autor. También se identifica la obra plástica por la unicidad, que significa la existencia de una íntima relación entre la creación como obra del intelecto humano y el soporte material en que esta se exterioriza. Las obras de arte forman parte de los bienes tangibles de colección, es decir, aquellos objetos que por su peculiar singularidad van, paulatinamente, aumentando su valor a través del tiempo, a la vez que su posesión puede aportar goce estético.

El mercado del arte tiene características propias que radican en la dedicación a la transacción de objetos únicos por lo que requiere que los agentes tengan un alto nivel de capacitación. Resulta entonces este tipo de negocio muy peculiar: por su objeto, los sujetos que intervienen y el mercado. Los que generalmente intervienen en este tipo de negocio son artistas, marchantes (comerciantes que compran y venden las obras, por lo que obtienen una comisión), galeristas (actúan como gestores o representantes artísticos y marchantes), coleccionistas, museos, consultores de arte, el Estado (posibilidad de ejercer derecho de tanteo y de retracto) y lo realizan mediante ferias de arte, casas de subastas y/o Internet.

Las desventajas que conlleva el comercio electrónico con obras plásticas cubanas son: inexistencia de una legislación nacional para la regulación del comercio electrónico en general y dentro de este las obras de arte; seguridad en la red y las transacciones; la gestión de los sistemas de pago; protección de los derechos de propiedad intelectual en el entorno digital; la legalidad de los contratos electrónicos; los aspectos de la jurisdicción en el ciberespacio sobre ley aplicable y resolución de conflictos; la falta de información y la desconfianza que suscita. Entre otros problemas básicos que implica están el encubrimiento de acciones delictivas, las repercusiones legales en las compraventas privadas y la falta de autenticidad de las obras. 


\section{BIBLIOGRAFÍA}

ALVARADO RIQUELME, M.; MACÍAS GUILLÉN, A. y NAVARRO HERAS, E., "Una reflexión sobre la valoración y presentación de las inversiones en obras de arte", XXI Congreso Anual AEDEM, Universidad del Rey Juan Carlos, Madrid, 6, 7 y 8 de junio de 2007, en MERCADO IDOETA, C. (coordinador). Ponencias, Vol. 1, 2007, p.41.

ÁlVAREZ NAVARRETE, L., Derecho de ¿autor? El debate de hoy, Editorial Ciencias Sociales, La Habana, 2006.

AA.VV., Metodología e investigación al servicio del Derecho, La Habana, Ediciones Ministerio de Justicia, 2013.

BAQUERIZO ESTUPIÑÁN, A. G., El e-commerce como herramienta de comercialización de pinturas de arte guayaquileñas en Estados Unidos, Trabajo de titulación especial para la obtención del grado de Magister en Negocios Internacionales y Comercio Exterior, Tutor del Trabajo Enrique Gavilanez García, Guayaquil, Ecuador, 2016.

CARRASCO ZAMBRANO, M. E., Plan de negocio de la comercialización de arte impreso de artistas visuales en el Ecuador usando TICs, Tesis para obtener el grado de Ingeniero en Ciencias Empresariales, Tutor de la Tesis Ing. José Macuy, Guayaquil, Ecuador, 2015.

CASABÓ ORTÍ, M. Á., La estafa en la obra de arte, Tesis doctoral, Tutores Jaime Peris y Amadeo Serra, Murcia, España, 2014.

COBO MARTínEZ, F. Procesos creativos en los espacios escénicos, Tesis Doctoral, Tutor de la Tesis Dra. Isabel Moreno Montoro, Jaén, España, 2013.

DE LA PARRA TRUJILlO, E., Derechos Humanos y Derecho de Autor. Las restricciones al derecho de explotación, 2da edición, Instituto de Investigaciones Jurídicas de la Universidad Nacional Autónoma de México, 2015.

DZIEMIDOK, B., "La expresión artística de la identidad cultural nacional", Criterios, No. 5, 1 de abril de 2011, La Habana, pp. 69-86.

ESCÁMEZ MARSILLA, J. I., Creación y promoción de una plataforma de venta on line de obras de arte pictóricas, Trabajo final de Carrera, Tutor José Mihuel Berné Martínez, Valencia, España, 2013.

FERNÁNDEZ NODARSE, F. A., "Sobre el comercio electrónico en la Web 2.0 y 3.0", Revista cubana de ciencias informáticas, Vol. 7, No. 3, julio - septiembre, La Habana, 2013, pp. 96-113.

FERRERO DIEZ CANSECO, G., "Derecho de Autor en la era digital y Tratados de Internet", Derecho \& Sociedad, No. 18, 2002, pp.163-169.

GARNELO DÍEZ, I. y SEDEÑO VALDELlOS, A. M., Más allá de los espacios alternativos situados más allá del cubo blanco. Prácticas expositivas en internet, disponible en: http://riuma.uma.es, consultado el 5 de febrero de 2018. 
Instituto Nacional de Defensa de la Competencia y de la Protección de la Propiedad Intelectual: Manual de Derecho de Autor para Entidades públicas, Perú, 2013, disponible en: http://repositorio.indecopi.gob.pe/handle/11724/4287, consultado el 17 de enero de 2018.

OLMEDO VELÁZQUEZ, E., "Limitantes en la adquisición de obras de arte en México", Revista Mexicana de Derecho de Autor, Año 2, No. 3, octubre 2013- marzo 2014, pp. 84-95.

ELIZALDE PERDIZ, R., "Obras en la rama denominada como arte aplicado", Revista Mexicana de Derecho de Autor, Año 1, No. 1, octubre 2012- marzo 2013, pp. 98-103.

LIPSZYC, D., Derecho de autor y derechos conexos, Editorial Félix Varela, La Habana, 1998.

MALFAVAUM-BELTRÁN, J. T., La obra de arte, su reproductibilidad técnica y masificación, disponible en: http://www.umar.mx/revistas/19/arte.pdf, consultado el 15 de enero de 2018.

MC. ANDREW, C., "El mercado español del arte en 2014", Cuadernos Arte y Mecenazgo, No. 3, España, 2014.

ORÉ SOSA, E., "Delitos contra el Derecho de Autor", REDUR Revista Electrónica de la Universidad de La Rioja, No. 9, diciembre 2011, pp. 335-355.

PEÑA VALENZUELA, D., "La piratería en Internet", Revista la Propiedad Inmaterial, No. 2, 2001, pp. 59-68.

PEÑA VALENZUELA, D., "Lex electrónica: ¿mito o realidad? Perspectiva desde la contratación por medios electrónicos", Revista la Propiedad Inmaterial, No. 7, 2003, pp. 103-116.

PEÑA VALENZUELA, D., "Reflexión conceptual sobre la ciberpiratería", Revista la Propiedad Inmaterial, No. 10-11, 2007, pp. 149-156.

PEÑUELAS I REIXACH, L., Valor de mercado y obras de arte, Editorial Marcial Pons, Madrid, 2005.

PÉREZ-CALERO SÁNCHEZ, L. A., "Mercado del arte e intermediarios: una perspectiva actual", Laboratorio de Arte, No. 23, 2011, España, pp. 537-550.

PÉREZ GALLARDO, L. B. (director), Comentarios al Código Civil Cubano, Tomo 1, Vol. 1, Editorial Universitaria Félix Varela, La Habana, 2013.

RAPA ÁlVAREZ, V., Manual de Obligaciones y Contratos, Tomo II, Editorial Félix Varela, La Habana, 2009.

TRIANA LÓPEZ, B., "Reflejo de las especiales características de la obra plástica en la sucesión mortis causa del Derecho de Autor", Anuario de la Facultad de Derecho, Vol. XXVII, 2009, pp. 373-409.

VALDÉS DÍAZ, C. del C., Estudios cubanos sobre Derecho de Autor y derechos conexos, Ediciones ONBC, La Habana, 2014.

WAELDER, P., "Coleccionar intangibles: estrategias de venta de obras de net art", en ALSINA, P. (coordinador), Historia(s) del arte de los medios, Artnodes Revista de Arte, Ciencia y Tecnología, No. 13, 2013, pp. 111-119. 
WUHL, F., "¿Derecho de autor o propiedad intelectual? Nuevas posibilidades en internet", en CASANOVAS, I.; GÓMEZ, M. G. y RICO, E. J. (editores), Actas de las III Jornadas de Investigación en Edición, Cultura y Comunicación, 2015, Buenos Aires, pp. 157-184. 